\title{
Recycling Agricultural Waste as a Part of Interior Design and Architectural History in Egypt
}

DOI: $10.21625 /$ archive.v1i1.116

\author{
Ayah Eldeeb ${ }^{1}$ \\ ${ }^{1}$ Interior designer, Masters degree, Alexandria University, Alexandria, Egypt
}

\section{Keywords}

Agricultural Waste Recycling -Sustainability -Interior design.

\begin{abstract}
Egypt is defined as an agricultural country where its people put all produced crops to use, whether as food or clothing. Agricultural wastes like straw, palm fronds, leaves and others are used in building and interior designing; they're part of an individual's lifestyle and culture. As time passed, all of this changed given that local agricultural materials were replaced with technology and new building materials. Farmers became uninterested in what happened to this waste that was burned as a means of disposal, this process has direct effects on public health and the environment.

This research examines the problem of palm fronds (agricultural materials) as a wasted renewable source in Egypt. It will attempt to find methods to link these materials with Egyptian handicrafts using new treatments in manufacturing with the cradle to cradle idea to produce compressed panels, wallpapers and other objects used in interior design. This research is important because it aims to find sustainable envi-ronmental materials with modern designs using agricultural waste.
\end{abstract}

\section{Introduction}

While Egypt is ranked third in the Middle East when it comes to the availability of agriculture waste that amounts to 71.5 million tons (dried weight in the oven), only $10 \%$ of it is reused in traditional works like cages and traditional furniture, while $90 \%$ of palm fronds are burned every year in Egypt. This causes environmental pollution and is a waste of sustainable construction materials that include highly recyclable contents, rapidly renewable and biodegradable products, and local resources.

Fronds are wastes from the date palm, which have already considerably attracted the attention of architects, engineers, and researchers in Egypt as a recycled sustainable material that is highly recyclable, rapidly renewable and biodegradable, and can reduce carbon emission and energy consumption. Environmentally friendly materials need to be carefully selected and applied to the proposed design to "satisfy the present needs without compromising the ability of future generations to meet their needs" (Brundtland, 1987).

For that, we should know characteristics of these materials and how they were used in the past and nowadays in Egypt.

\subsection{Palm Fronds (Phoenix dactylifera)}

Phoenix dactylifera, or the date palm tree, is perhaps best known for its sweet fruit but, as growers in the Middle East have known for thousands of years, its height typically reaches about 21-23 meters (69-75 ft). It grows as eiher a single stem or forming a clump with several stems from a single root system, its leaves can also be used in construction. The Middle East has $90 \%$ of the world's palm. 
The frond is a branch axis after the leaves of the plant are cut. The amount wasted was 965 thousand tons per year with an annual formation of 10 to 26 new leaves. These leaves vary in both length and weight. The length of fronds is typically 3 to $6 \mathrm{~m}$ (4m average) and have a normal life expectency of 3 to 7 years, while the length of one gazette is about eight meters in the type of pass entering the New Valley governorate, almost falling or trim. The color of a frond varies between the shades of green. Fronds are so strong, tough and crooked. Figure(1)
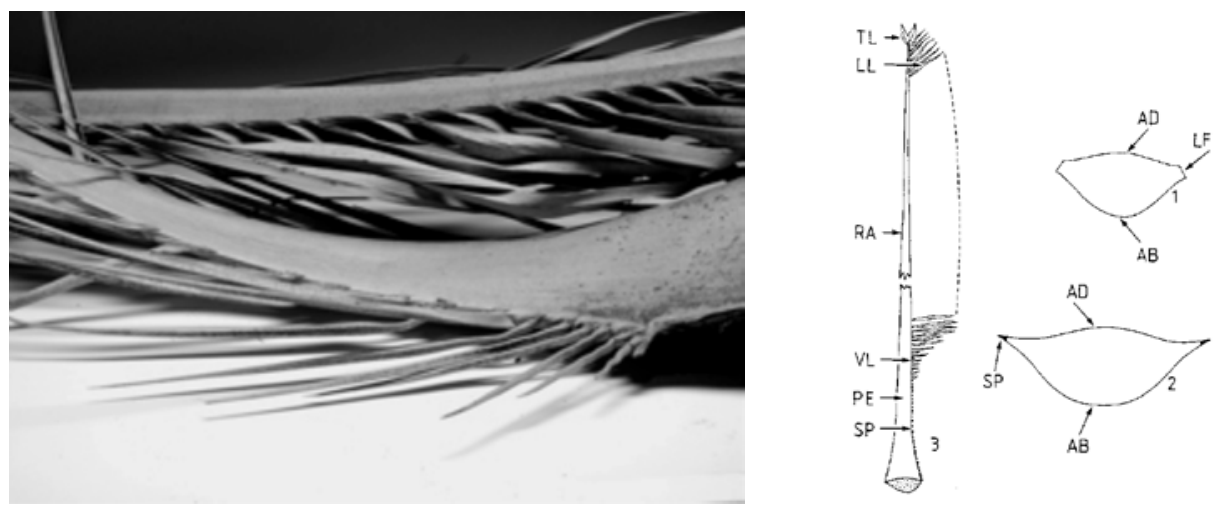

Figure1. Photographs and Caption of the form of palm fronds

\subsection{History of Palm fronds (Gireed)}

"Look under your foot and build,” Hassan Fathy said. Egyptian farmers have followed his words throughout the ages. The date palm was one of the pivots of economic, social and cultural life in this region from ancient times. In ancient Egypt, the heads of pillars in temples were resembled the growing top of the date palm. The date palm appeared frequently on walls of temples in different contexts revealing its significance in life in Egypt. According to Nubian (South Egypt) traditions, when a child is born, they plant a date palm for him or her.

In upper Egypt, each village had a number of palms grown along side it as it was believed that these trees provided a good base for the future economic life of the village. There hasn't been a big change in building materials in Egypt throughout the ages, locally available design and construction materials have always been used. Farmers built walls using mud, bricks and palm trunks, and the ceiling using palm fronds, leaves, and straw. Furniture was also made at home using the same materials. This way of building encouraged cooperation between people as even though each farmer built his own house (figure 2), he got help from the rest of the community and this became part of tradition. Palm fronds have also been commonly used in developing fishing materials and as fuel in rural ovens.

Nowadays, gireed is mostly used for making wooden cages for birds. However, Egyptian Farmers no longer care about building with old and natural materials as they have been replaced with concrete and metal.
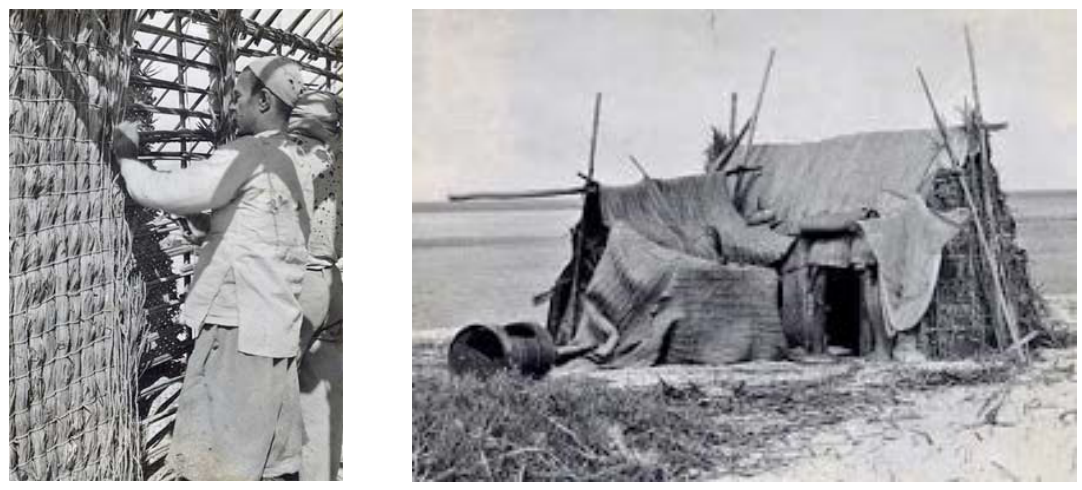

Figure 2. Photographs of palm fronds and leaves house manually made in Egypt

\section{Palm Frond Using}

\subsection{Palm Fronds/Gireed Architecture (Arish Building)}

Lifestyle, climate and available building materials are major influences in the architectural style of traditional houses anywhere. Arish architecture is an old Arab form of architecture founded in the Arabian Peninsula given the abundance of palm trees. Even though the concept of Arish building is very simple, its design is sophisticated and is strong enough to resist the extreme desert climate in the Arabian peninsula for thousands of years. 
Nowadays, bedouins, who are nomadic by nature, still live in animal hide tents during the winter, and arish shelters during the hot summer months. These palm frond shelters were airy in the summer, as they allowed for ventilation and were either square or rectangular with flat roofs or triangular tent-like structures. Barasti or arish houses were built by the first construction wooden frames of split-palm trunks or any other wood that was available.

The palm fronds were then used in two different ways: as straight poles with the leaves stripped off for creating screens, and with the leaves still on as a roof thatch. They collected some of the palm leaves together vertically and trimmed them well, they would then tie them together using ropes of palm fiber and support them using palm trunks, and finally covered the rood withpalm leaves, (figure 3).
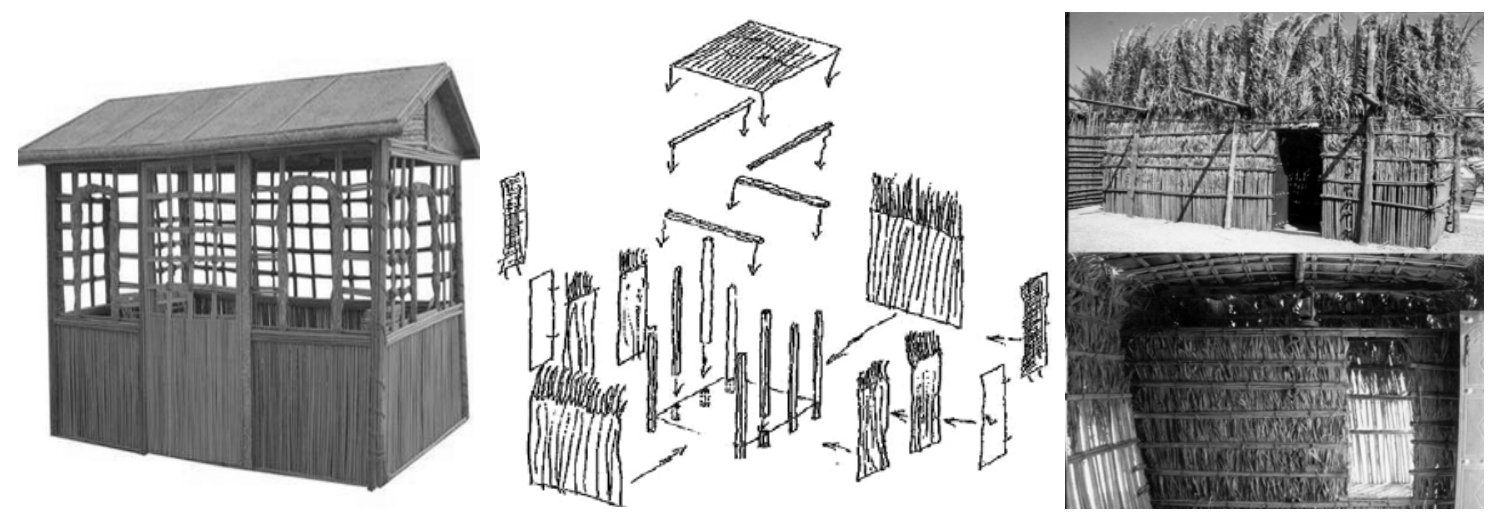

Figure 3. Caption of old Arish from a palm fronds and leaves.

\subsection{Gireed Furniture: Cages Furniture}

In the same way cages were produced in a way that preserves the identity of Egyptian raw material, palm fronds were used to make furniture. This was done by carpenters in the cottage industry who manufacture products using palm fronds and sell them to the local market i.e. local Dumyat families such as areas of Abu Nomros and Shabramant Giza Governorate. This reflects the element of post-production in any design or artistic process today.

Using the midribs of the preferred varietiesof palm fronds, because there are quality differences, the edges, where the pinnae were attached, are firstly removed by a stripping knife, after which they are cut into pieces of standard lengths and, since they are tapered, assembled in groups with equal diameters. The smaller diameters are further smoothed and rounded for their intended use. The thicker lengths that are to be perforated are leveled in order to at least have two flat surfaces. After having marked them, the holes are perforated by a punch (driven in by a mallet) an operation in which both the operator's hands and feet actively and efficiently participate. In assembling the crate, the thinner rods are knocked down the holes making use of a flat thick piece of iron, after which superfluous material is cut and trimmed using a knife and collected together.

With the new design, Studio Meem product line "Off the Gireed" furniture included seating, tables, and shelving units, which are chemically treated to extend its life cycle. Off the Gireed furniture explore possibilities of material, process, place and cultural context that are embedded in an everyday work and re-contextualized in innovative ways to create fresh meanings and uses. Off the Gireed furniture is used to reinvigorate the traditional craft of palm cage making, using a renewable material source and drawing appreciation to these crafts. This product line was awarded Red Dot and Good Design Awards. fig (4),
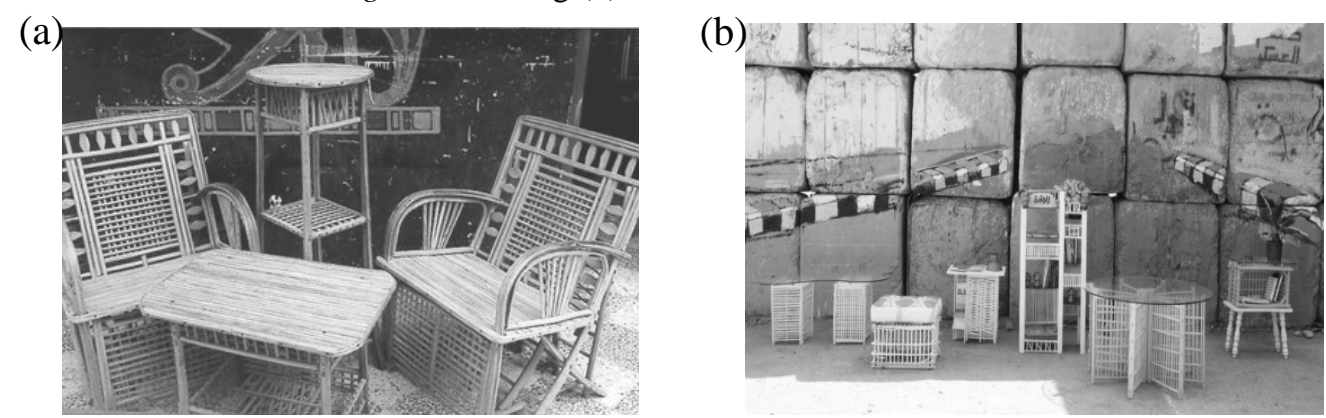

Figure 4. (a) Photographs of traditional palm leaves furniture (b) Studio Meem furniture designs. 


\section{Palm frond/(DPLM) board}

\subsection{Palm frond Board/(DPLM) Production (In Egypt)}

The cradle to cradle idea is one of the sustainable design benefits that invlves economic decisions in life-cycle functionality. Its design depends on making product parts that are easy to separate after use, they are not only efficient, but also essentially waste free. Handicrafts and local materials make this easy. In an effort to revive traditional Egyptian handicrafts to compete with the globalized market, the Egyptian Society for Endogenous Development of Local Communities has started producing local handicrafts furniture and carpentry, which are made of palm fronds that were grown in one of the lowest-income villages in Upper Egypt, called Al-Zayat village. The process of turning the fronds into products comes in two stages.

First, the fronds are turned into wood fig (5). The second stage is shaping the wood into different kinds of products such international-standard wooden tables, mirror frames, parquet flooring, and wall cladding.

(a)

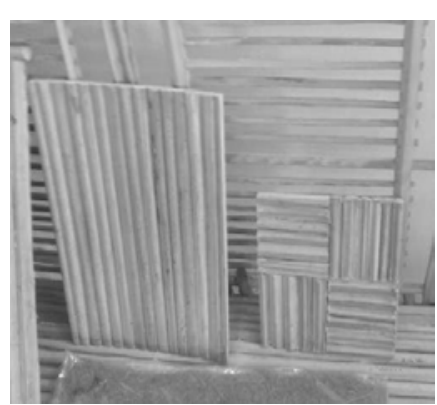

(b)

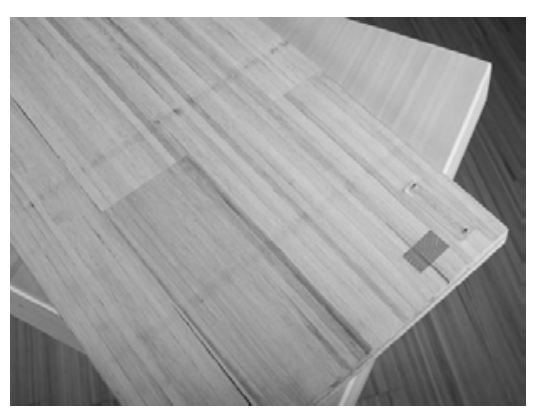

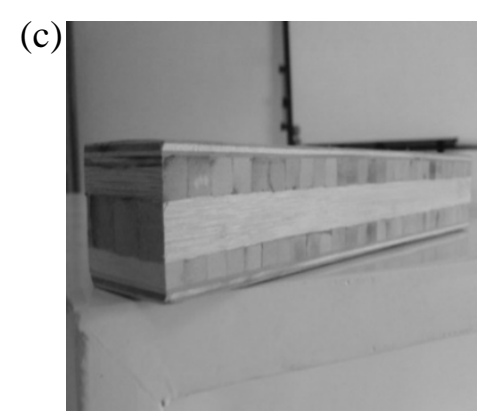

Figure 5. (a) Samples cut out from DPLM board , (b) DPLM board after treated (c) DPLM double board as a sandwich panel.

(a)(c)Source:[Egyptian Association for self-development of local communities, Egypt, researcher photo]

Hamed El-Mously, an engineering professor at Ain Shams University, developed innovative technologies to transform midrib, the strong central spine in the middle of palm leaves, from a soft living material into hardened wooden strips. The research included testing different species of date palm, and developing eco-friendly techniques for solar drying and gluing together midribs to wooden blocks.

Gireed is bent and its shape is not straight, so workers change this shape into a more uniform one so it can be compressed and produce wooden blocks. The production technique is simple, but the quality assurance process designed for palm fronds/gireed involves a cooling system that controls the level of oxygen, carbon dioxide and nitrogen inside a storage room.

Palm fronds/gireed mats and strips are further developed to produce a number of decorative board sizes with different patterns. It is carried out by craftsmen with machines manufactured locally, which cut gireed into three pieces and stored in preparation for the cutting operation (Altsudaib). This process converts all the pieces of the three to a group of small pieces by cutting it lengthwise. This is followed by the aggregation stage, where all the pieces are collected together in a small rectangular shape going through a pressing process.

Then starts the trimming process in which carpenter carefully shapes a piece of wood with equal dimensions to obtain the required sizes accurately, and collected pieces together to produce a large wooden board that's ready for use in many product industries. Gireed produces high-quality alternative wood from palm midribs, that aim to replace commercially imported wood with eco-friendly, locally made Jereed alternative wood. Fig. (6).

(a)

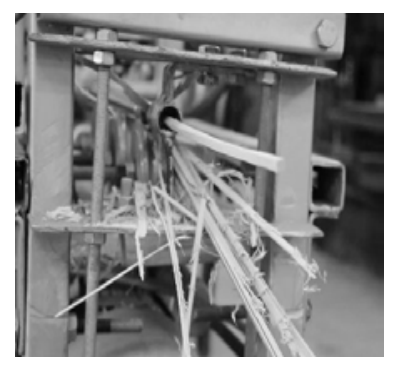

(b)

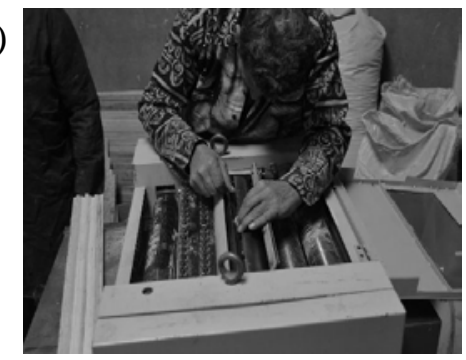

(c)

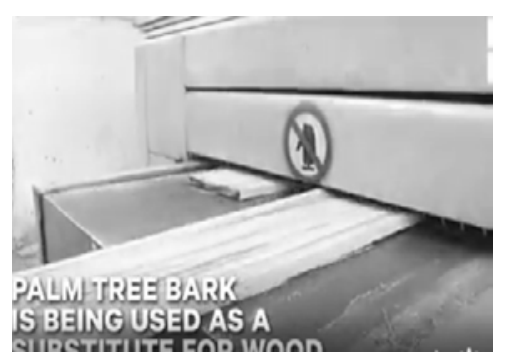

Figure 6. Photographs of (a) Cutting process, (b) Trimming process (c) Collect and Compress process.

\subsection{Palm frond Board/ (DPLM) Experimental}

The first step in this methodology involved the conduction of tests to determine the physical and mechanical properties of palm midribs and their comparison with the corresponding properties of wood. The research findings, 
(figure 7), have shown that palm midribs enjoy physical and mechanical properties falling within values pertinent to known wood species as spruce and beech.

Hence the date palm wood is a good candidate for the development of efficient and safe insulating materials. Palmwood properties were tested in a lab at Munich University in Germany to verify its suitability as a substitute for hardwood. Results proved that palm wood is very competitive with standard wood.

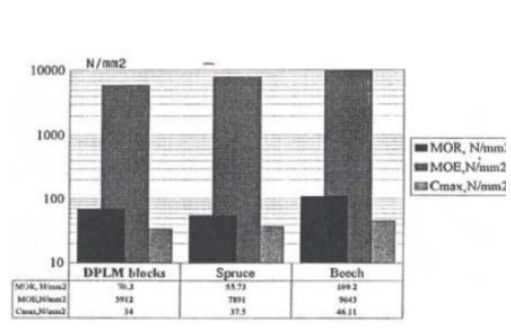

(a)

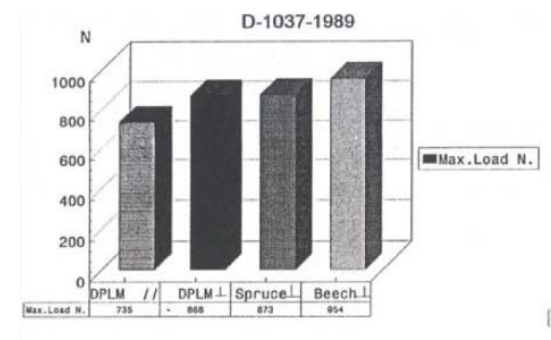

(b)

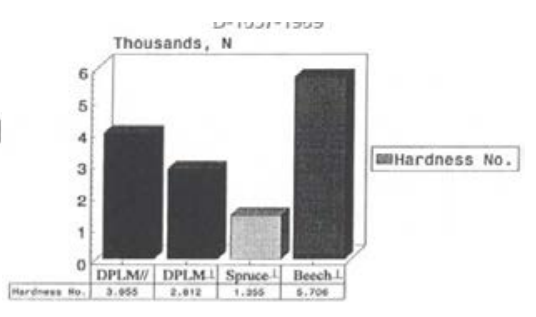

(c)

Figure 7. Comparison between the mechanical properties of DPLM and several wood specics:

$$
\begin{aligned}
& \text { 1. MOE, MOE and } C_{\max } \text {. } \\
& \text { 2. Nail with drawal test. } \\
& \text { 3. Hardness test [19]. }
\end{aligned}
$$

[This research has been awarded the Euromat-97 conference prize for the best poster, 21-23 April 1997, Maastricht (Appendix 3)]

The research was conducted to determine the tensile strength of the outer 1.25-mm layer of the midrib. The research results (See Table 1$)$ clearly indicate that the outer layer of the midrib enjoys a tensile strength $(\sim 25 \mathrm{~kg} / \mathrm{mm} 2)$ comparable with that of commercial steel. As far as the specific strength is concerned, i.e. tensile strength per unit weight, the outer layer is 4 times higher than steel. This indicates that the palm midrib's outer layer is a super strong material that could find wide applications in industrial composites. Table(1)

Table 1.The values of tensile strength and specific tensile strength for palm midrib outer layer, compared with several wood species and steel.

\begin{tabular}{|l|c|c|}
\hline \multirow{2}{*}{ Material } & Tensile strength & Specific tensile strength \\
\cline { 2 - 3 } & $\left(\mathrm{N} / \mathrm{mm}^{2}\right)$ & $\left(\mathrm{N} / \mathrm{mm}^{2}\right)\left(\mathrm{g} / \mathrm{cm}^{3}\right)$ \\
\hline Outer layer & 248 & 196 \\
\hline Inner layer & 70 & 86 \\
\hline European read pine & 78 & 142 \\
\hline Beech & 97 & 140 \\
\hline Steel 37 & 367 & 46 \\
\hline
\end{tabular}

\subsection{Palm frond Board Example(DPLM)}

\subsubsection{Palm frond Board Arabesque}

The Arabesque (Mashrabiah مشربية handicrafts are a part of our cultural heritage. The Arabesque items are being used in furniture, windows, and partitions (figure 8). The drastic increase in the price of imported beech wood, usually used for Arabesque, has led to the shrinkage of demand on Arabesque handicrafts. Therefore, it was thought that the replacement of beech wood by the cheap locally available palm midribs may open the way for the revival of Arabesque handicrafts, especially in rural areas. The Center for the Development of Small-Scale Industries launched, in July 1995, a project in the Dakhla oases in the New Valley Governorate to disseminate Arabesque handicrafts using palm midribs as a raw material. A training center was established to train the beneficiaries (figure 8), who obtain their lathes on a loan basis and produce at home. The project has shown great success turning the poor, especially women, to autonomous producers and entrepreneurs and transforming the idea of the use of trees pruning products as a substitute for imported wood into reality.

The project shows great potential in disseminating a new culture of sustainable use of renewable material resources in rural and desert communities in the whole Arab region. 
(a)

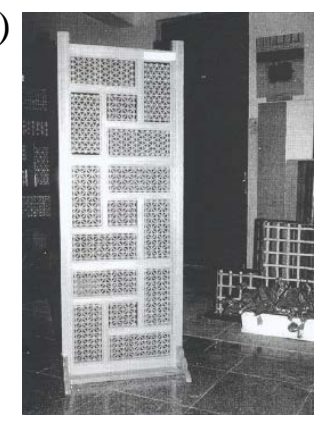

(b)

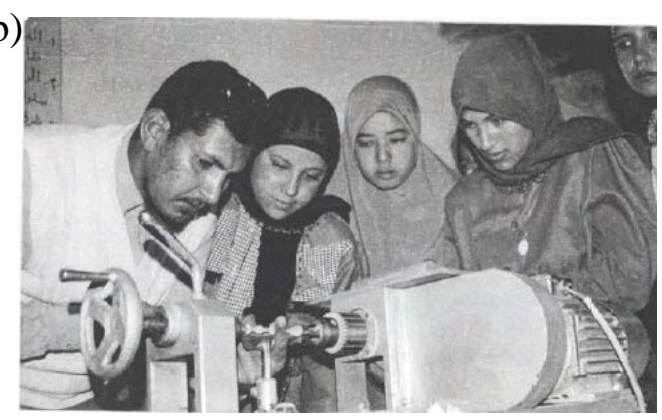

Figure 8. Photographs of (a) apartition of the Arabesque (b)Training beneficiaries on Arabesquehandicrafts. [Source: El-Mously, H.I.Centre For Development of Small-Scale Industries]

\subsubsection{Palm Frond Board Furniture (DPLM)}

A number of Egyptian designers and craftsmen in Alqayat Village used modern designs to develop a series of handmade furniture pieces from palm fronds boards. Egyptians furniture designers like Mohamed Saeed designed many of the tables and chairs, Rania Salah designed many of the lighting units and trays, and designer Aklijo designed desk units. Lighting indicated the extent of the exploitation of the potential of the raw material, which relates to nature by developing these items by hand and mastering the technique, this allowed the team to test new dimensions in artisan capability (figure 9). These furniture pieces are characterized by their design simplicity, lightness of the philosophy of weight, it's cost-effective. They are used in interior spaces, which confirms that an environmentally friendly product does not adversely affect the environment and furniture should generally be in line with the nature of the place in which it resides.

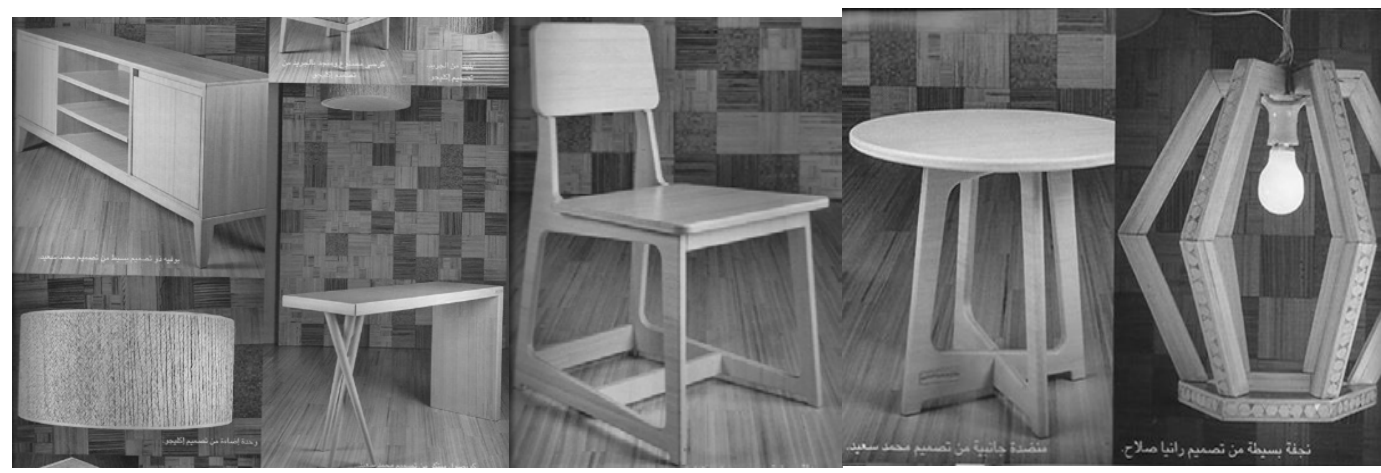

Figure 9. Photographs of tables and chairs, lighting units and desk units

\subsubsection{Palm frond Parquet Flooring}

Palm frond boards are used, in cooperation with the Egyptian Association for Self Development of Local Communities where the panels are manually cut into rectangles. These panels serve as a "building block" in the parquet board manufacturing and they are covered with a layer of beech wood, or any other desired material and painted according to the desired color.

The floors of the most important domestic blank selectors are the ones with the most friction, and thus the most ones that physically and visually affect the user. Palm frond parquet tiles in the flooring industry is a great victory for this raw material that is manufactured from plant residue (figure 10). They compete with natural wood and surpass wood in terms of their texture that helps prevent slipping.
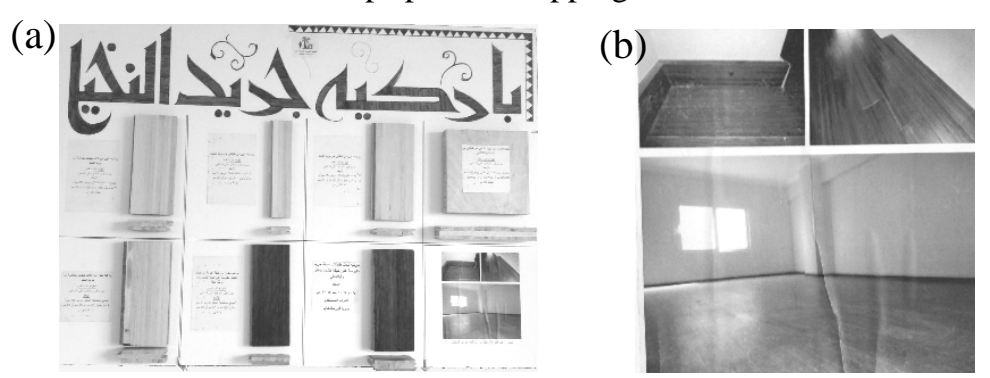

Figure 10. Photographs of (a) Palm frond parquet Flooring (b) Room with Palm frond parquet Flooring covered with a layer of beech wood Source:[Egyptian Association for self-development of local communities, Egypt, researcher photo] 


\section{Conclusion}

This paper presents the history of the use of palm fronds in Egypt since ancient times and the extent of deterioration and neglect. This research urges manufacturers to reconsider the use of this wasted raw materials and try to save it for the provision of local building materials, preserving the environment and reducing the consumption of natural resources.

Palm fronds passed aboard several tests successfully and proved its superiority over the types of non-available wood locally in Egypt, where it already has great potential for use in sustainable designs, and the evolution of the industry from the traditional manual methods, like the cage industry, to technologically advanced methods that allow for the production process to be completed using palm fronds.

\section{References}

1. Agoudjila,B.J.,Benchabaneb,A.,Boudennec,A.,Ibosc,L.,Foisc,M, 2010. Renewable materials to reduce building heat loss: Characterization of date palm wood. February-March 2011, Elsevier.

2. Agricultural Production, FAO, 1995.

3. AWRU (2005) Agricultural Waste in Egypt, Agricultural Waste Recycling Unit (AWRU), Ministry of State for Environmental Affairs (MSEA), Egyptian Environmental Affairs Agency (EEAA). Cairo, Egypt

4. Crops for Sustainable Enterprise, 2000. Design for Sustainable Development. The European Foundation for the Improvement of Living and Working Conditions, Dublin, Ireland.

5. El-Deeb HM, Lashin SM, Arab YA (2007) Distribution and pathogenesis of date palm fungi in Egypt. Acta Hort 736:421-429

6. El-Mously, H.I. 2005. The Palm Fibres for the Reinforcement of Polymer Composites: Prospects and Challenges, A paper presented to the First Ain Shams International Conference on Environmental Engineering, Egypt.

7. El-Mously, H.I., 2001. The industrial use of the date palm residues: an eloquent example of sustainable development. 2nd Inter. Conf. on Date Palms, Al-Ain, United Arab Emirates Univ., pp. 872-879.

8. El-Mously, H.I., 2003. The Date Palm as a Basis for Environment-Friendly Industries Beginning from the Rural Areas. The International Palm Conference, held in the King Saud University (El-Quaseem Branch).

9. El-Mously, H.I.,1996 Achievements-to-Date and Future Prospects of Research on Use of Date Palm Leaves’ Midribs as a Substitute for Sawn Wood. Conf., Challenges of Sustainable Dev. Organized by INES, Amsterdam.

10. GHOSH S. K. ; NAG D. ; NAYAK L. K., 2009. Composite particle boards from Date-Palm Leaves - A viable substitute of wood/plywood products, Journal of the Indian Chemical Society A. vol. 86, $n^{\circ}$ 8, pp. 857-862 .

11. Schwab. A.,2008. - Sustainability in Commercial building, Building Materials \&Technology Congress, Kuwait.

12. Taha,I., Steuernagel,L., Ziegmann.G., 2007. Optimization of the alkali treatment process of date palm fibres for polymeric composites Compos Interf, Germany, pp. 669-684.

13. The Egyptian Association for self-development of the communities for Local.2004. Palm as a source of industrial raw materials and construction materials, Egypt. p. 7.

14. Vogtländer. J.G., Hendriks. Ch. F., Brezet. J.C., 2001. Allocation in recycle systems: an integrated model for the analyses of environmental impact and economic value. p 344-355. 